\title{
Research on Evaluation of Technological Innovation Ability about Guangxi Non-Ferrous Metal Industry based on RBF Neural Network
}

\author{
Peng Liu, Jun Hong \& Xin Wang \\ School of Electrical Engineering, Guangxi University \\ 100 Da Xue Road, Nanning 530004, Guangxi, China \\ Lan Huang \\ Guangxi Electric Power Institute of Vocational Training \\ 39 Keyuan Road, Nanning 530007, Guangxi, China
}

\begin{abstract}
This paper made an analysis about advantage and disadvantage of Guangxi non-ferrous metal industry. Based on the RBF neural network model, the paper then gave an evaluation of technological innovation ability about non-ferrous metal industry in Guangxi. And then, the paper proposed some suggestions how to better develop non-ferrous metal industry in Guangxi.
\end{abstract}

Keywords: Non-ferrous metal industry, Technological innovation ability, RBF neural network model

\section{Introduction}

Non-ferrous metals industry (short for NFMI) is one of Chinese pillar industries in national economy. In Guangxi, NFMI has played an important part in promoting economic growth and is been cultivated as one of hundred billion dollars industries. With the western development strategy and open development strategy of the northern Gulf Economic Zone in Guangxi, NFMI in Guangxi has entered a new period of rapid development.

Technological innovation is an inexhaustible motive force of industry development. Effective technological innovation about non-ferrous metal industries in Guangxi could improve resource utilization ratio and economical benefit. The improvement of technological innovation would be built on scientific evaluation.

Artificial neural network which could imitate human brain to process data and information is suited to analysis and processing of complex information. This paper tried to evaluate technological innovation ability with this theory.

\section{The current situation of NFMI in Guangxi}

\subsection{The developing situation of NFMI in Guangxi}

Guangxi has rich resources of non-ferrous metal. There are 115 kinds of minerals discovered, in which 89 kinds have been known reserves, including manganese, tin, bauxite, tungsten, antimony, zinc, indium and other 20 kinds of minerals. These resources have concentrated distribution and good quality. For example, bauxite is the only one in China which can be used to produce aluminum oxide by pure Bayer's method in Guangxi. The resources of tin, antimony, indium, rare earths in Guangxi are well-known all over the world except the resource of bauxite.

The production of non-ferrous metal industry in Guangxi has developed at the speed of $12.6 \%$ per year over the past 50 years, and the growth rate reached to $18.7 \%$ per year after reform and opening up in China. Now the non-ferrous metal industry in Guangxi can produce 450,000 tons of alumina, 200,000 tons of electrolytic aluminum, 170,000 tons of electrolytic zinc, 150,000 tons of zinc oxide, 100 tons of indium, 35,000 tons of tin and 50,000 tons of aluminum every year.

\subsection{The current situation of technological innovation about NFMI in Guangxi}

There are 246 non-ferrous metal enterprises and 39 large and medium non-ferrous metal enterprises in Guangxi. Guangxi government expands science and technology R\&D input in order to change non-ferrous metal resources into local economic advantages. In 2007, expenditures of science and technological activities about non-ferrous metal 
industry in Guangxi amounted to 296.94 million Yuan which increased 42.35 percent. There were 5857 engineering and technology people, increased $27.9 \%$, and $665 \mathrm{R} \& \mathrm{D}$ people, increased $8.13 \%$. The number of patents was 28 compare with 21 in 2006, and industrial labor productivity was 320.5 thousand Yuan per person, increased of 122.2 thousand Yuan compared with 2006.

"The Decision of Three-year (2008-2010) Plan about Scientific Development in Guangxi” pointed out: We should give priority to the development of key competitive industries, extend industry chain, and enhance industrial concentration. We would pay main attention on the development of food-processing industry, non-ferrous metal industry, automobile industry, petroleum chemical industry, metallurgical industry, machining industry and power industry. The goal is that the sales income of every industry is more than 100 billion Yuan every year in near future." Currently, the Research Center of indium antimony tin has been established and a new industrial area which has 3333 hectares (500 acres) is being built by Huaxi Group. Guangxi also has a steel industry, a state quality inspection center of indium and a standard warehouse and electronic trading platform of indium in LiuZhou.

\section{Artificial neural network evaluation models}

\subsection{The evaluation indexes}

"The analysis report about ability of independent innovation of Chinese enterprises" which was proposed by Economic Situation Monitoring Center of National Bureau of Statistics in 2006, pointed out the evaluation indexes of technological innovation. This paper combined with these evaluation indexes and the general process of technological innovation, and then proposed new evaluation indexes including input of technological innovation, output of technological innovation and marketing of technological innovation.

The evaluation indexes of technological innovation ability about Non-ferrous metal industry are divided into three levels, which contain 10 sub-factors, as shown in Table 1.

\subsection{The model}

RBF (Radial Basis Function) model is a kind of artificial neural network, which can achieve quick calculation and zero error.

\section{(1) Data standardization}

In order to eliminate the different dimensionless of data and fix data in the same interval, we can accomplish data standardization of sample data and target data through formula $\mathrm{x}=\left(\mathrm{x}_{\mathrm{j}}-\mathrm{x}_{\mathrm{jmax}}\right) /\left(\mathrm{x}_{\mathrm{jmax}}-\mathrm{x}_{\mathrm{jmin}}\right)$, where variable $\mathrm{x}$ means standardized data, variable $x_{j}$ means the exact value of simple in column $\mathrm{j}, \mathrm{x}_{\mathrm{jmax}}$ means the maxima and $\mathrm{x}_{\text {jmin }}$ means minima.

(2) RBF network training

In the Matlab7.0 environment, we accomplish the network training of standardized data through procedure net $=$ newrb(x,y).

(3) Network simulation

In the Matlab7.0 environment, we obtain the evaluation results $y^{\prime}$ through procedure $y^{\prime}=$ sim (net, $\left.x^{\prime}\right)$, where $x^{\prime}$ means training data, net means the name of trained network. We can also analyze the results by outputting weights.

\section{Evaluation and suggestions}

\subsection{The evaluation of technological innovation ability about Guangxi's NFMI}

This paper collected sample data on non-ferrous metals industry to train the network (data source: "China Statistical Yearbook 1999-2007"), and then collected relevant statistics on non-ferrous metal industry in Guangxi in 2007 as target data (data source: "2008 Guangxi Statistical Yearbook"). We accomplished data standardization through formula $\mathrm{x}=$ $\left(\mathrm{x}_{\mathrm{j}}-\mathrm{x}_{\mathrm{jmax}}\right) /\left(\mathrm{x}_{\mathrm{jmax}}-\mathrm{x}_{\mathrm{jmin}}\right)$, as shown in Table 2 , in which the target values of training samples were given by experts according to five levels.

In the Matlab7.0 environment, we firstly train RBF neural network through procedure net $=$ newrb (x, t, $0.001,0.1,11$, 1) (error: $10^{-3}$, which is shown as Figure 1). Then we use the trained network net to test sample data through procedure $\mathrm{y}=\operatorname{sim}($ net, $\mathrm{x} 1)$, where $\mathrm{x} 1$ means test sample data, evaluation results is given by $\mathrm{y}(\mathrm{y}=2.45)$. At last, we obtain the weights through procedure $\mathrm{w} 1=$ net. iw $(1,1)$ and $\mathrm{w} 2=$ net. $\mathrm{lw}(2,1)$, as shown in Table 3 . In Table 3 , Wi means weight of each index, row CHN is the calculated result of weight value, and row GX is the conclusions of previous studies.

\subsection{The analysis of evaluation results}

As shown in Table 2, the evaluation result is given by $\mathrm{y}(\mathrm{y}=2.45)$, which is less than the mean value of nation's NFMI (4.69). Therefore, technological innovation ability about non-ferrous metals industry in Guangxi is at a medium, lower than the standard of nation. Contrasting the weight of indexes from Table 3, we could know that there is some superiorities and inferiority of technological innovation ability about non-ferrous metals industry in Guangxi as 
following.

(1) A. input of technological innovation funds

Inequality $\mathrm{W} 1(\mathrm{CHN})>\mathrm{W} 1(\mathrm{GX})$ which is given by the weight value of $\mathrm{A} 1$, means non-ferrous metals industry has a lower input of research and development funds about non-ferrous metals industry in Guangxi. Approximately W2 $(\mathrm{CHN})$ equals W2 (GX), which is given by the weight value of A2, means there are many non-ferrous metals enterprises in Guangxi. Inequality W3 $(\mathrm{CHN})>>$ W3 $(\mathrm{GX})$, which is given by the weight value of A3, means that the proportion of research and development personnel is too small to reach the national level.

(2) B. output of technological innovation

Inequality $\mathrm{W} 4(\mathrm{CHN})>\mathrm{W} 4(\mathrm{GX})$ which is given by the weight value of $\mathrm{B} 1$, means new products have a low production and non-ferrous metals enterprises in GungXi could not get more economical Benefit from technological innovation. Inequality W5 (CHN)> W5 (GX) which is given the weight value of B2, means non-ferrous metals enterprises in GungXi do have less core technology. Inequality W6 (CHN)> W6 (GX) which is given by the weight value of B3, means the number of skilled workers is small in the industry. Approximately W7 (CHN) equals W7 (GX), which is given by the weight value of B4, means the level of technical staff is close to the national level. Inequality W8 (CHN)> W8 (GX) which is given by the weight value of B5, means equipments in the industry are out of date.

(3) C. marketing of technological innovation

Inequality W9 $(\mathrm{CHN})>>$ W9 $(\mathrm{GX})$, which is given by the weight value of $\mathrm{C}$, means the level of on-line marketing about GungXi's non-ferrous metals enterprises is the lowest in china. Inequality W10 (CHN)>W10 (GX), which is given by the weight value of $\mathrm{C} 2$, means marketing system of nonferrous metals industry in Guangxi is not perfect, there is a gap between production and marketing. Inequality W11 (CHN) $>$ W11 (GX), which is given by the weight value of $\mathrm{C} 3$, means nonferrous metals industry in Guangxi has a market share of new product.

\subsection{The suggestions}

This paper proposes some suggestions base on above analysis.

(1) Increase input of research and development

Enough capital could provide a good environment for people to engage in scientific and technological innovation. Furthermore, increase input of research and development has great significance for sustainable development of non-ferrous metals industry in Guangxi.

(2) Improve the construction of technical innovation group

High quality researchers are an important part of technical innovation group and senior technicians are also a necessary part. Enterprise should strengthen the cooperation among Industries, Universities and Research in finance, credit, tax and so on. Enterprise also should make full use of national funding, establish special fund of Research and fully raise the motivation of university, enterprise and society.

(3) Invest the construction of information system of enterprise

Constructing information system is systematic engineering. In one hand, enterprise should find ways to raise capital. In the other hand, enterprise should combine technical innovation project and information construction.

(4) Strengthen data resources management

Building information resource data base of enterprise and using the function of Data mining could help the enterprise find its marketing position.

\section{Conclusions}

This paper, based on RBF neural network theory, made a quantitative analysis and comprehensive evaluation of technological innovation ability about non-ferrous metals industry in Guangxi with software Mat lab 7.0. Comparing with the weight of each index of national non-ferrous metals industry, we concluded that the technological innovation ability in Guangxi is at middle level of national non-ferrous metals industry. But there is some inferiority such as input of technological innovation, output of technological innovation and marketing of technological innovation. In order to improve the technological innovation ability about non-ferrous metals industry in Guangxi effectively, it is necessary to increase input and improve the ability of changing knowledge into products, but necessary to strengthen the information management of enterprise.

\section{References}

Bin Zhu. (2009). Research on the Fuzzy Comprehensive Evaluation Methods and its application in the differences of regional innovation capabilities of Fujian province Based on a BP Network. techno-economic and management study, 3, 38-40. 
Hong Ren, Yuwei Liu and Lianjing Li. (2009). The Status quo, Problems and Countermeasures for the Scientific Development of Non ferrous Metal Industry in Guangxi. Enterprise Science And Technology \& Development, 262, 13-14.

Jiaji Fu. (1998). Technological Innovation. Beijing: Tsinghua Press, (Chapter 1).

Table 1. The evaluation indexes of technological innovation ability about NFMI

\begin{tabular}{|c|c|c|}
\hline \multicolumn{3}{|c|}{ the evaluation indexes of technological innovation ability } \\
\hline $\begin{array}{l}\text { A. input of technological } \\
\text { innovation }\end{array}$ & $\begin{array}{l}\text { B. output of technological } \\
\text { innovation }\end{array}$ & $\begin{array}{l}\text { C. marketing of } \\
\text { technological innovation }\end{array}$ \\
\hline $\begin{array}{l}\text { A1. research and } \\
\text { development funds } \\
\text { A2. the proportion of } \\
\text { enterprises in the industry } \\
\text { A3. the proportion of } \\
\text { research and development } \\
\text { personnel }\end{array}$ & $\begin{array}{l}\text { B1. output of new product } \\
\text { B2. patent owned /number of } \\
\text { patent applications } \\
\text { B3. number of skilled workers / } \\
\text { number of employed persons } \\
\text { B4. the level of technical staff } \\
\text { B5. the level of equipment }\end{array}$ & $\begin{array}{l}\mathrm{C} 1 \text {. the level of on-line } \\
\text { marketing } \\
\mathrm{C} 2 \text {. adaptability of } \\
\text { marketing system } \\
\text { C3. market share of new } \\
\text { product }\end{array}$ \\
\hline
\end{tabular}

Table 2. Standardized data

\begin{tabular}{|c|l|l|l|l|l|l|l|l|l|l|l|}
\hline year & A1 & A2 & A3 & B1 & B2 & B3 & B4 & B5 & C1 & C2 & C3 \\
\hline 1998 & 0.471 & 1.000 & 0.673 & 0.995 & 0.526 & 0.927 & 0.113 & 1.0 & 1.0 & 1.0 & 0.6 \\
\hline 1999 & 0.800 & 0.792 & 1.000 & 0.984 & 0.161 & 0.907 & 0.135 & 0.5 & 1.0 & 1.0 & 0.85 \\
\hline 2000 & 0.314 & 0.773 & 0.565 & 1.000 & 0.516 & 0.875 & 0.164 & 0.5 & 1.0 & 1.0 & 0.80 \\
\hline 2001 & 1.000 & 1.000 & 0.510 & 0.969 & 0.000 & 0.796 & 0.192 & 0.5 & 1.0 & 1.0 & 0.80 \\
\hline 2002 & 0.071 & 0.773 & 0.184 & 0.938 & 0.419 & 0.738 & 0.201 & 0.5 & 1.0 & 1.0 & 0.85 \\
\hline 2003 & 0.128 & 0.792 & 0.000 & 0.909 & 0.494 & 0.660 & 0.161 & 0.5 & 0.5 & 0.5 & 0.9 \\
\hline 2004 & 0.000 & 0.773 & 0.347 & 0.532 & 0.430 & 0.523 & 0.140 & 0.0 & 0.0 & 0.5 & 0.85 \\
\hline 2005 & 0.400 & 0.792 & 0.021 & 0.659 & 0.526 & 0.126 & 0.048 & 0.0 & 0.0 & 0.0 & 0.6 \\
\hline 2006 & 0.485 & 0.735 & 0.021 & 0.000 & 0.602 & 0.000 & 0.000 & 0.0 & 0.0 & 0.0 & 0.0 \\
\hline GX & 0.928 & 0.000 & 0.347 & 0.932 & 1.000 & 1.000 & 1.000 & 1.0 & 0.0 & 0.5 & 1.0 \\
\hline \multicolumn{2}{|c|}{$2.45,2.59,3.23,2.91,4.05,5,6.41,7.23,8.36$} & & & AVG=4.69 \\
\hline
\end{tabular}

Table 3. Weight values

\begin{tabular}{|l|c|c|c|c|c|c|c|c|c|c|c|}
\hline & W1 & W2 & W3 & W4 & W5 & W6 & W7 & W8 & W9 & W10 & W11 \\
\hline CHN & 0.861 & 0.792 & 1.0 & 0.984 & 0.161 & 0.907 & 0.135 & 0.5 & 1.0 & 1.0 & 0.85 \\
\hline GX & 0.373 & 0.700 & 0.2 & 0.715 & 0.041 & 0.531 & 0.129 & 0.28 & 0.5 & 0.6 & 0.68 \\
\hline
\end{tabular}


Performance is 1.2326 e-032, Goal is 0.001

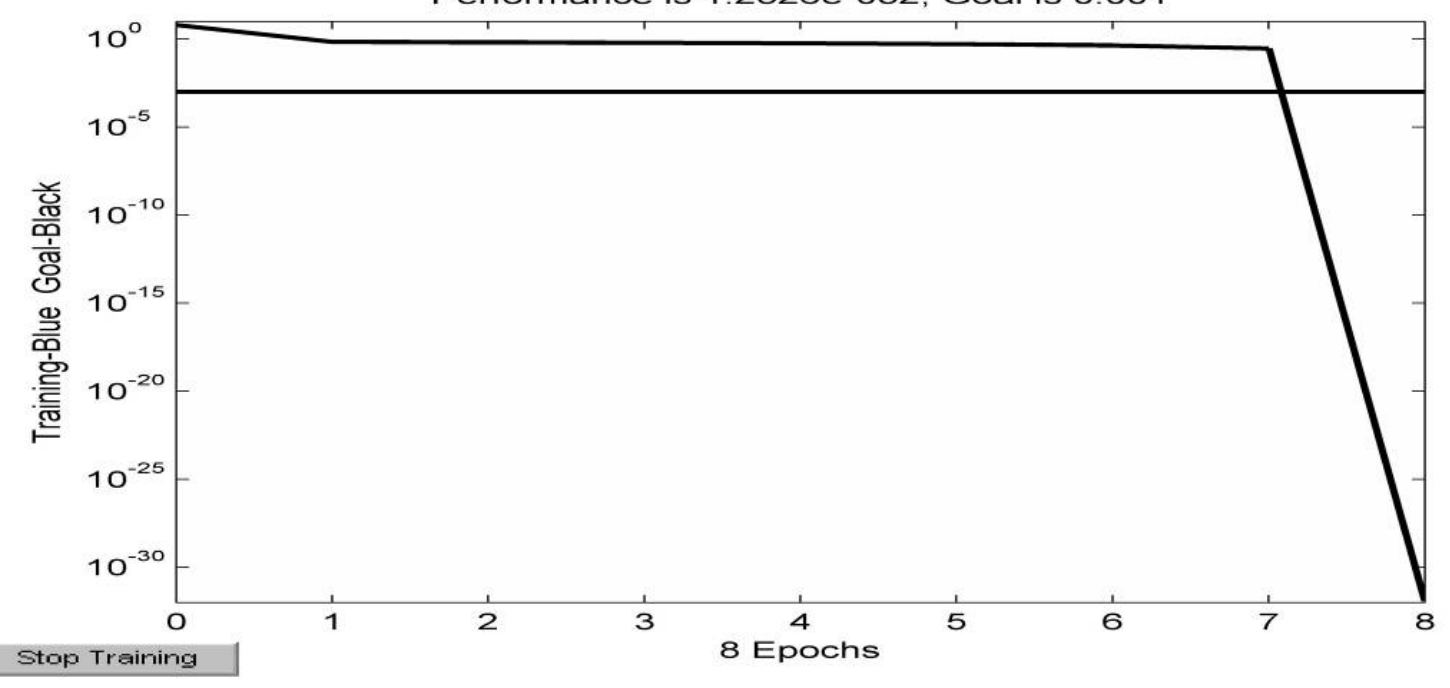

Figure 1. The error of training 